\title{
INVESTIGATION OF SENTINEL-1 TIME SERIES FOR SENSITIVITY TO FERN VEGETATION IN AN EUROPEAN TEMPERATE FOREST
}

\author{
Marlin M. Mueller ${ }^{1,2}$, Clémence Dubois $^{1}$, Thomas Jagdhuber ${ }^{3,4}$, Carsten Pathe ${ }^{1,2}$, Christiane Schmullius ${ }^{1}$ \\ ${ }^{1}$ Department for Earth Observation, Institute of Geography, Friedrich Schiller University, Jena, Germany - (marlin.markus.mueller, \\ clemence.dubois, carsten.pathe, c.schmullius)@uni-jena.de \\ ${ }^{2}$ Institute of Data Science, German Aerospace Center, Jena, Germany \\ ${ }^{3}$ Microwaves and Radar Institute, German Aerospace Center, Wessling, Germany - thomas.jagdhuber@dlr.de \\ ${ }^{4}$ Institute of Geography, University of Augsburg, Augsburg, Germany
}

Commission III, WG III/2

KEY WORDS: Sentinel-1, time series, backscatter, phenology, undergrowth, seasonality, fern

\begin{abstract}
:
In this study, a dense Copernicus Sentinel-1 time series is analyzed to gain a better understanding of the influence of undergrowth vegetation, in particular of eagle fern (Pteridium aquilinum), on the C-band SAR signal in a temperate forest in the Free State of Thuringia, Germany. Even if signals from the ground below the canopy may not be expected at C-band, previous studies showed seasonal fluctuations of the backscatter for temperate forests without canopy closure, notably for evergreen coniferous stands. Many factors can be responsible for these observed fluctuations, but in this study, we analyze one possible factor: the presence of undergrowth vegetation, in particular, of fern. Especially, the Sentinel-1 backscatter signal is analyzed for different acquisition configurations regarding its temporal and its spatial stability at different growth stages. This time series study shows that a difference of backscattered signal of up to $0.7 \mathrm{~dB}$ exists between forest patches with a dense fern density in the understory and the ones with low undergrowth vegetation. This signal difference depends on the season and is remarkably strong comparing winter (no fern undergrowth) with summer (major fern undergrowth).
\end{abstract}

\section{INTRODUCTION AND STATE OF THE ART}

Forests are a key element in the global carbon cycle with immense carbon storage potential in highly heterogenous ecosystems (Garestier et al. 2008). In an effort to understand the impact of climate change and as a vital socio-economic resource, the monitoring of forest stands has long been a part of remote sensing research (White et al. 2016; Holmgren and Thuresson 1998). With the launch of daylight- and weather-independent radar satellites, combined with the ability to penetrate tree canopies at longer wavelengths, radar remote sensing has played a major role in forest monitoring in the last decades (Quegan et al. 2000; Shimada et al. 2011).

While there is a growing understanding of the multitude of influencing external parameters on the SAR signal itself, it is often a complex and demanding process to separate the individual influencing parameters such as moisture, structure or temperature. Monteith et al. (2018) investigated multiple external factors, like temperature, wind speed, vapor-pressure deficit (VPD) or vegetation water content (VWC), on P- and L-band time series with ground-based radar systems. These studies provide sensitivity analyses in high temporal resolution but are often restrained to a small region of interest.

With the launch of the Copernicus Sentinel-1 constellation (Sentinel-1A and -1B), the European Space Agency provides free access to C-band SAR data with high spatial (up to $10 \mathrm{~m}$ ) and temporal resolution (up to 6 days). Particularly in Europe, the dense time series with a short revisit time of at least 6 days enable analyses of bio-physical vegetation dynamics at unprecedented temporal scale.

Since then, seasonal behavior of Sentinel-1 backscatter time series of different natural land cover types has been observed and analyzed (Dubois et al. 2020; Vreugdenhil et al. 2018). The observed periodicity in signal variation can be related to different plant and soil properties that have individual (diurnal to yearly) cycles (Monteith and Ulander 2018). Recent publications focus on agricultural monitoring to assess seasonal influences and compare phenological stages to backscatter signals (Rütschi et al. 2018; Stendardi et al. 2019). Similar analyses, focusing on the phenology monitoring of deciduous and coniferous forests, have been presented (Frison et al. 2018; Dostálová et al. 2018). These studies have shown that very high temporal resolution is necessary to effectively analyze phenological (vegetation structure) influences on SAR backscatter.

As the importance of the utilization of these dense time series becomes more apparent, research focuses on developing approaches using advanced temporal metrics, like multitemporal recurrence plots for deforestation mapping (Cremer et al. 2020). Similarly, Dostálová et al. (2021) applies temporal signatures of different vegetation types for a more advanced landcover classification on European scale. While some of these approaches utilize (qualitative) phenological data for comparative measures, they do not focus on analyzing the quantitative influence of external parameters such as moisture, VPD or VWC. Instead, they concentrate on the general ability of SAR data to predict or classify surface features.

With the shifting focus on temporal analyses, a profound understanding of the underlying temporally guided influences on the radar signal is necessary. One parameter that is not well investigated is the influence of undergrowth vegetation on the Cband signal from temperate forests having no canopy closure. Larger wavelengths (e.g., L-band or P-band) should penetrate the canopy of temperate forests and can potentially return backscattered signal from the undergrowth (Joshi et al. 2017). However, the influence of the undergrowth vegetation on smaller wavelengths, like $\mathrm{X}$ - and C-band, is not proven and will depend on the canopy structure, height and density (Garestier et al. 2008).

In this paper, we analyze Copernicus Sentinel-1 time series over a period of 4.5 years in combination with meteorological data as well as optics-based (Sentinel-2) tree cover density information to investigate a link between fern undergrowth and the radar backscatter signal in temperate coniferous forests. For this, we

\footnotetext{
* Corresponding author
} 

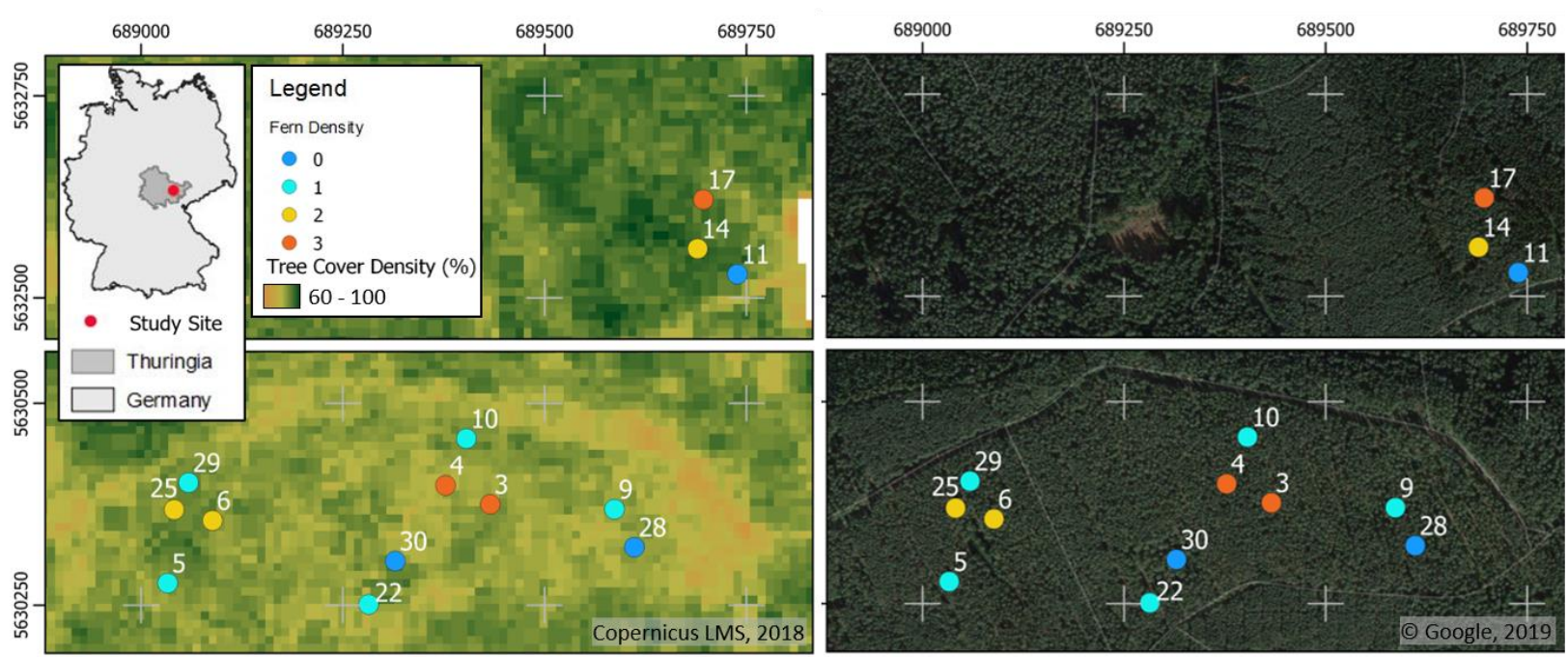

Figure 1: Geographical location of the study area in the Free State of Thuringia, Germany and reference points for fern measurements (color-coded) in the northern (top) and southern (bottom) part of the study area as well as the Sentinel-2 based tree cover density (TCD) of the coniferous forest surrounding the study site (left). (Copernicus Land Monitoring Service 2020)

individually analyze polarizations, pass directions and meteorological seasons of the available time series.

Section 2 provides an overview of the study site and presents the utilized satellite datasets, the in situ fern measurements and the auxiliary data. Section 3 defines the applied methodology of the initial time series extraction; the data stability analyses at spatial and temporal scales as well as the concluding comparison of fern growth and radar backscatter. In Section 4 differences of backscatter depending on the presence of fern undergrowth are presented based on seasonal variation and acquisition scenarios. Finally, the results and principal outcomes are discussed in Section 5.

\section{STUDY AREA AND DATA}

This study focuses on a small part of a coniferous temperate forest in central Thuringia, Germany. In the following section, the applied datasets and their sources are presented.

\subsection{Study area}

The study site is located within the federal forestry district "JenaHolzland" in the southeast of the Free State Thuringia in central Germany (see Fig. 1). The intensively managed forest consists of evergreen pine and some spruce trees. It is an old growth forest stand with large canopy gaps due to management activities in the southern part and well-developed undergrowth (see Fig 2). The average tree cover density (TCD) in the southern part is $85 \%$, while the northern region shows a TCD of $92 \%$. The undergrowth consists principally of fern, blueberries and regrowing trees like young birch. In 2019 the southern part of the study site was further thinned by logging activities. The average tree height ranges from 20 to $25 \mathrm{~m}$ (Thiel et al. 2020). The elevation of the study site ranges from $350 \mathrm{~m}$ in the northern part to $370 \mathrm{~m}$ (a.s.l) in the southern part with gentle terrain topography. The yearly temperature averages around $10^{\circ} \mathrm{C}$ with average precipitation between 600 and $650 \mathrm{~mm}$ (Bauer 2013).

\subsection{Fern measurements}

From April 2020 through October 2020, fern vegetation parameters, i.e., fern height and phenological stage, was monitored in biweekly field campaigns for the 14 locations shown in Fig. 1. The locations correspond to the position of well-
Table 1: Fern height $[\mathrm{cm}]$ and corresponding phenological stage at each measurement location.

\begin{tabular}{|c|c|c|c|c|c|c|c|c|c|c|c|}
\hline & \multicolumn{11}{|c|}{ Station number } \\
\hline $\begin{array}{c}\text { Measurement } \\
\text { date }\end{array}$ & 9 & 10 & 4 & 3 & 22 & 29 & 25 & 6 & 5 & 14 & 17 \\
\hline 14.04.2020 & & & 15 & & & & & 0 & & & \\
\hline 30.04 .2020 & 18 & 20 & 50 & 75 & 21 & 23 & 43 & 28 & 32 & & \\
\hline 15.05 .2020 & 31 & 41 & 100 & 107 & 56 & 35 & 51 & 56 & 28 & 75 & 61 \\
\hline 29.05 .2020 & 64 & 61 & 77 & 86 & 39 & 39 & 61 & 53 & 37 & 87 & 89 \\
\hline 17.06.2020 & 111 & 68 & 128 & 111 & 56 & 54 & 68 & 75 & 44 & 108 & 111 \\
\hline 03.07.2020 & 96 & 76 & 119 & 97 & 41 & 40 & 63 & 62 & 49 & 145 & 93 \\
\hline 23.07 .2020 & 104 & 82 & 141 & 101 & 48 & 52 & 68 & 74 & 48 & 160 & 109 \\
\hline 06.08 .2020 & 93 & 79 & 125 & 105 & 51 & 49 & 70 & 86 & 51 & 147 & 120 \\
\hline 30.09 .2020 & 104 & 68 & 133 & 107 & 48 & 49 & 61 & 80 & 40 & 137 & 99 \\
\hline 28.10 .2020 & 100 & 73 & 133 & 99 & 49 & 53 & 57 & 80 & 52 & 115 & 111 \\
\hline
\end{tabular}

known soil moisture measurement stations, which ensures that the measurements are taken at the same location each time. The locations were categorized according to their respective fern densities, which was determined and categorized into four classes by expert inspection. A fern density of 0 means there is no fern at this location, a fern density of 1 means the undergrowth is made of approx. $33 \%$ of fern, a fern density of 2 of $66 \%$, and the third class means the undergrowth presents full and exclusive fern cover. According to Fig. 1, three locations have a fern density of 0 , six locations a fern density of 1 , three locations a fern density of 2 and three locations a fern density of 3 . An

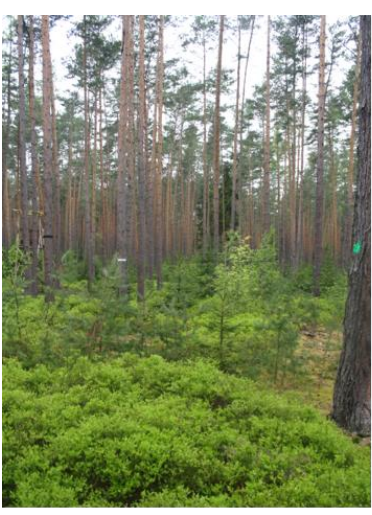

a

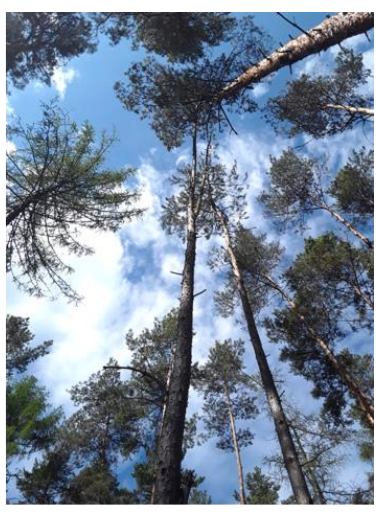

b
Figure 2: Current (2020) in situ vegetation cover situation of the study area: a) understory vegetation and tree density; b) tree canopy (bottom-up). 


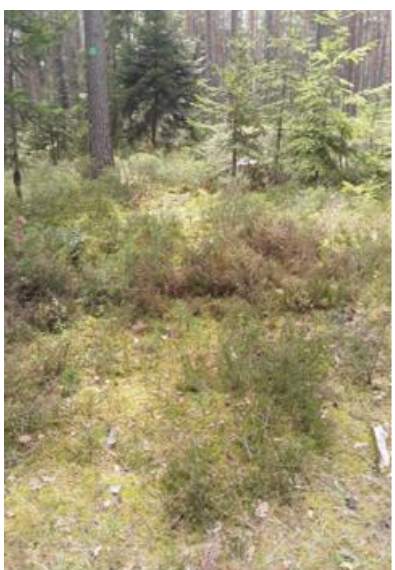

a

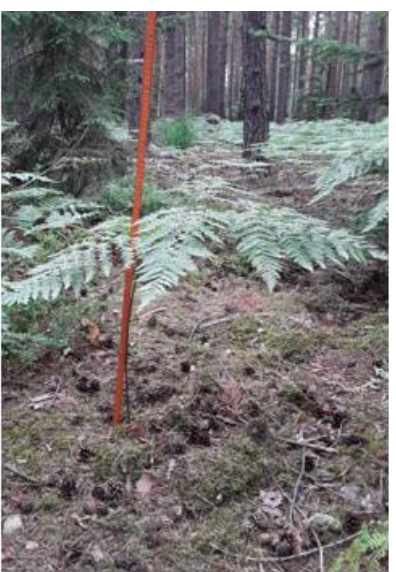

b

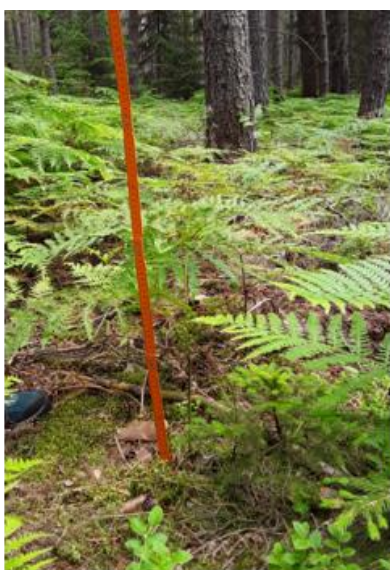

$\mathrm{C}$

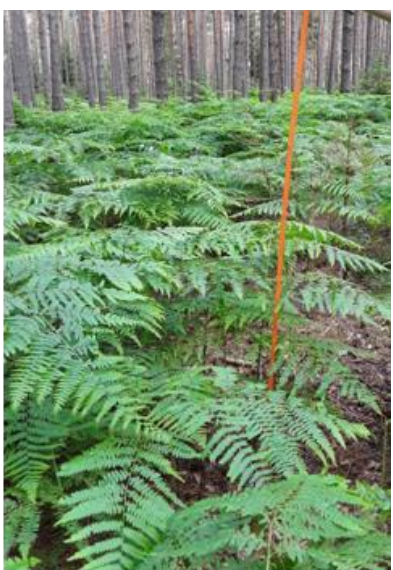

d

Figure 3: Determined fern density classes: a) overview of forest floor and class 0 (no fern), 14.06.2020; b) class 1 (approx. 33\% fern cover), 17.06.2020; c) class 2 (approx. 66\% fern cover), 17.06.2020; d) class 3 (full fern cover), 17.06.2020.

overview of the different fern density classes is presented in Fig. 3. Although fern represents the most important undergrowth vegetation of the selected test sites, it is visible from Fig. 2a that other shrub vegetation is also present on some sites, especially blueberry bushes or small trees. Those may also affect the temporal Sentinel-1 signal but were not considered during this study. In this study, only class 0 (no fern) and class 3 (all fern) are analyzed. For each measurement date, three ferns, which were representative of the area, were measured with a folding meter stick at each location in a radius of approx. $5 \mathrm{~m}$. The three measurements were then averaged to provide one height estimate and one phenological stage per location per date. Table 1 summarizes the dates of the fern measurements, as well as the corresponding derived height and phenological stage.

Strandberg et al. (1997) defined seven development and growth stages of leatherleaf fern leaves. We also used seven stages to describe the phenology of the eagle fern (Pteridium aquilinum) of our study area. However, we defined them slightly differently, according to both moisture and structural changes of the ferns, which corresponds to the relevant characteristics for the radar signal. We considered stages where the stems elongated, stages where the leaves were fully developed providing a horizontal moisture layer a few meters above ground, or stages where the fern was drying out. The seven phenological stages (PS) were defined as follows:

PS1: sprouts with rolled fern fronds (vertical stem) PS2: sprouts rolling out fern frond (long vertical stem) PS3: fern frond unfolding, leaflets

PS4: fully developed fern (horizontal leaf cover)

PS5: beginning of browning (moisture content diminishes)

PS6: completely brown but still standing (dried out) PS7: dead eagle fern
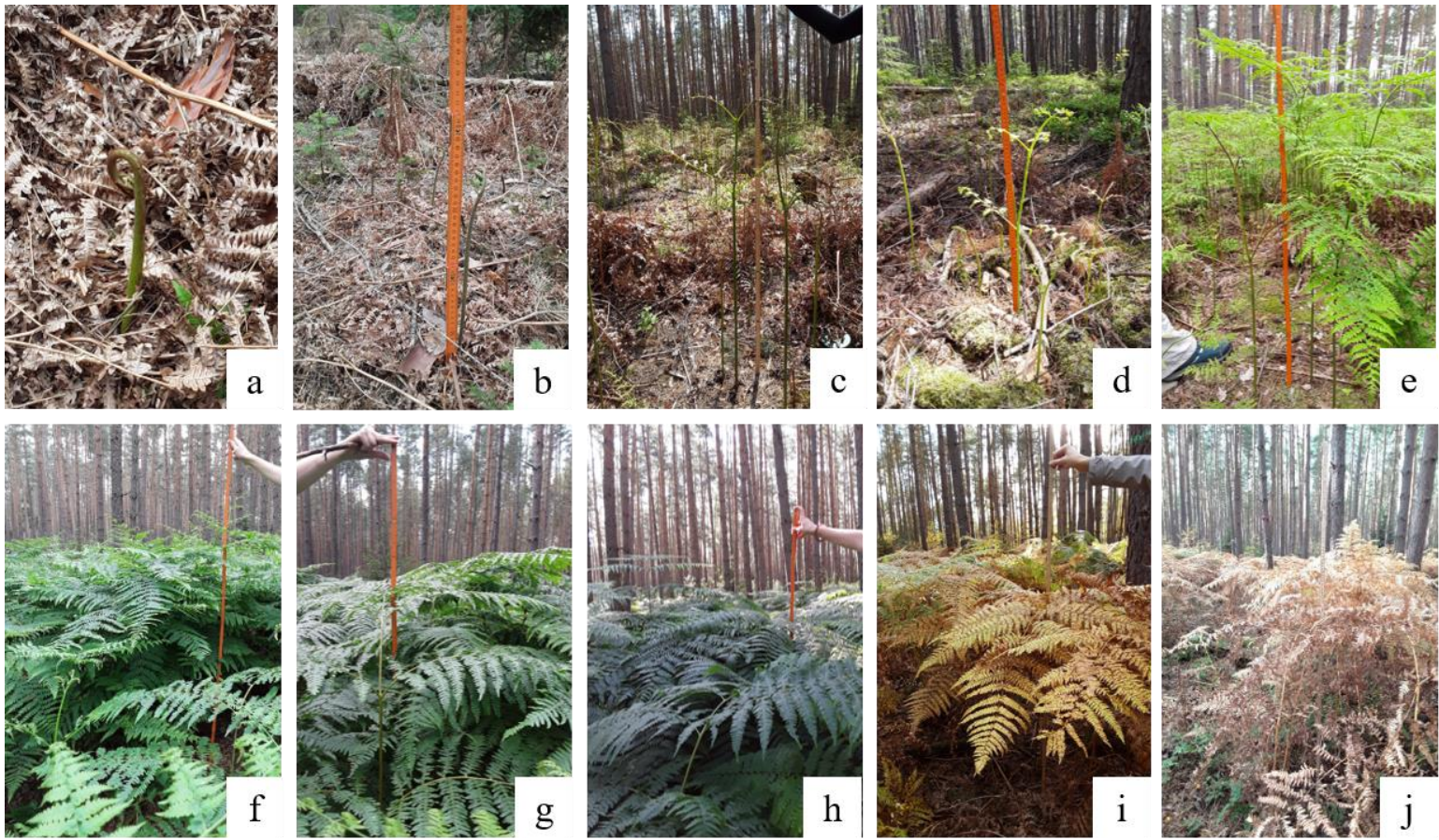

Figure 4: Phenological stages (PS) of fern in the study area at the different measurement dates: a) 14.04.2020, PS1; b) 30.04.2020, PS2; c) 15.05.2020, PS3; d) 29.05.2020, PS3; e) 17.06.2020, PS4; f) 03.07.2020, PS4, g) 23.07.2020, PS4; h) 06.08.2020, PS4; i) 30.09.2020, PS5; j) 28.10.2020, PS6. 
Table 2: Overview of the Sentinel-1 acquisition parameters.

\begin{tabular}{|c|c|c|c|c|c|}
\hline Dataset & $\begin{array}{c}\text { Flight } \\
\text { Direction }\end{array}$ & $\begin{array}{c}\text { Relative } \\
\text { Orbit }\end{array}$ & $\begin{array}{c}\text { Inc. } \\
\text { Angle }\end{array}$ & $\begin{array}{c}\text { Number of } \\
\text { Acquisitions }\end{array}$ & $\begin{array}{c}\text { Timespan of } \\
\text { Acquisition }\end{array}$ \\
\hline $\mathbf{1}$ & Descending & 168 & 38.9 & 256 & $\begin{array}{c}07 / 14 / 2016- \\
12 / 14 / 2020\end{array}$ \\
\hline $\mathbf{2}$ & Ascending & 44 & 36.5 & 246 & $\begin{array}{c}07 / 05 / 2016- \\
12 / 17 / 2020\end{array}$ \\
\hline $\mathbf{3}$ & Ascending & 117 & 44.7 & 234 & $\begin{array}{c}07 / 17 / 2016- \\
12 / 16 / 2020\end{array}$ \\
\hline
\end{tabular}

The different stages are shown in Fig. 4 for the different measurement dates, except for PS7, which can be seen in the background of Figure $4 \mathrm{a}$ and $4 \mathrm{~b}$.

A decrease of fern height is noticeable for a few stations between 15.05.2020 and 29.05.2020, due to frost conditions in early May 2020. The fern growth observed between 30.04.2020 and 15.05.2020 was stopped (see Figure 4c, frostbitten fern) and new fern grew between early May and 29.05.2020, leading to a temporary decrease of the measured fern height (Fig. 4d). The fern measurements have only been conducted in 2020, but it is assumed in the following that the behavior and fern location is the same for the previous years.

\subsection{Sentinel-1}

We used Copernicus Sentinel-1A and -1B dual-polarimetric (VV, VH) interferometric wide swath (IW) ground range detected (GRD) C-band SAR time series data over a period of 4.5 years with a mean temporal resolution of six days providing high temporal sampling to map temporal dynamics in forest ecosystems (Tab. 2). To ensure equal intervals between acquisitions, only data since the launch of Sentinel-1B in mid2016 was considered. Each scene has been processed to RTC product using pyroSAR, with application of orbit files, radiometric calibration to gamma0, multilooking to $20 \mathrm{~m}$ pixel size, radiometric terrain flattening and geocoding (Truckenbrodt et al. 2019). With a spatial resolution of 20 meters, the detail is sufficient to cover the fern measurement sites within multiple pixels. We independently examined co- and cross-polarized SAR data. The study site has only a small extent in east-west direction and therefore exhibits a small range $\left( \pm 0.1^{\circ}\right)$ of incidence angles for each SAR dataset. As the incidence angle of scenes from relative orbit number 117 shows a high deviation from the other scenes, we only utilized scenes from relative orbit number 44 and 168 in the following analysis to allow a comparison of descending and ascending datasets that is independent from the incidence angle.

\subsection{Auxiliary data}

Ground temperature (2m) and precipitation data from a nearby weather station operated by the Thuringian State Office for Agriculture (TLLLR) was acquired for the same timespan as the SAR observations. The daily averages for the dates of the Sentinel-1 data acquisitions were extracted and used for the analysis. The Copernicus Land Monitoring Service (CLMS) TCD dataset of 2018 was used to determine the average tree cover density for the study site (Copernicus Land Monitoring Service 2020). It has a spatial resolution of $10 \mathrm{~m}$ and ranges from $0 \%$ (no tree cover) to $100 \%$ (no ground surface visible). The TCD product is based on optics-based Sentinel-2 data and has a user's and producer's accuracy above $92 \%$.

\section{METHODOLOGY}

In this section, we describe the process of extracting time series data using a Python framework and how we analyze the influence of fern undergrowth using different backscatter metrics.

\subsection{Data pre-processing}

The time series datasets have been created by developing an Opensource Python framework (1) (github.com/marlinmm/SentinelTime) utilizing the packages rasterio, fiona and GDAL. Most of the pre-processing steps are automated to allow fast and easy adaptability. Time series datasets are extracted for each fern measurement location site from the SAR datasets based on the mean of all SAR pixels which touch the $20 \mathrm{~m}$ square bounding box around each measurement location (thin lines in Fig. 5). For each class, all pixels are spatially averaged to maximize the robustness of each time series.

These time series are analyzed for different polarizations (VV, $\mathrm{VH}$ ) and pass direction (asc. and desc.). We apply a Gaussian filter with a kernel size of two sigma (standard deviation) on the time series to de-emphasize short-term (e.g., weekly) dynamics for the benefit of seasonal dynamics (thick lines in Fig. 5). We use meteorological data for a detailed comparison and temporal correlation with the C-band SAR signal (Fig. 5).

\subsection{Spatial and temporal stability analysis}

This study aims at analyzing backscatter differences between different fern classes. As the observed backscatter difference between the different fern classes as well as the number of data points is rather low (see section 4.1.), it is necessary to analyze its stability to ensure that the observed difference between class 0 (no fern) and class 3 (all fern) is significant compared to the measurement accuracy of Sentinel-1 backscatter (Schmidt et al. 2018; El Hajj et al. 2019). For this, we analyzed both the stability of the difference information for different spatial extents and temporal samples.

We consider that the inherent radiometric uncertainty of Sentinel1 is balanced using backscatter difference in a spatially averaged window and over a long period of time. To confirm this assertion, we show the maximum impact of considering different spatial extent and temporal density on the backscatter difference.

To evaluate spatial stability of our data, we compared the averaged backscatter time series of the bounding box (see 3.1) to the backscatter signal of the single central pixel over the fern measurement site. This should reveal the influence of the local neighborhood.

The temporal consistency of the SAR backscatter signal dynamics was evaluated by a stepwise reduction of the temporal resolution of the series. To ensure an unbiased reduction, the reduction omitted every other data point by half and only used every fourth data point for a reduction to $25 \%$ of the original dataset. This kept the whole 4.5 years of the time series, but gradually decreased the temporal density of the samples in the series. The goal of these reductions was to analyze if the considered temporal sampling has an influence on the backscatter difference, whilst keeping the seasonal variations of the time series.

\subsection{Visibility of fern in the SAR signal}

The objective of the study is to analyze, if the SAR time series behave differently for the individual test site locations that have different fern density classes. This would imply an influence of the fern undergrowth on the backscattered signal. The nearest neighboring measurement sites of class 0 and 3 are selected to be compared in the analysis. Studies suggest, a thin canopy is necessary to enable the C-band signal to pass through the canopy to lower parts of the forest structure (Garestier et al. 2008; Townsend 2002). Therefore, the TCD layer was used to examine the tree cover density for each measurement site. As the fern growing season starts in mid-spring and reaches its maximum 


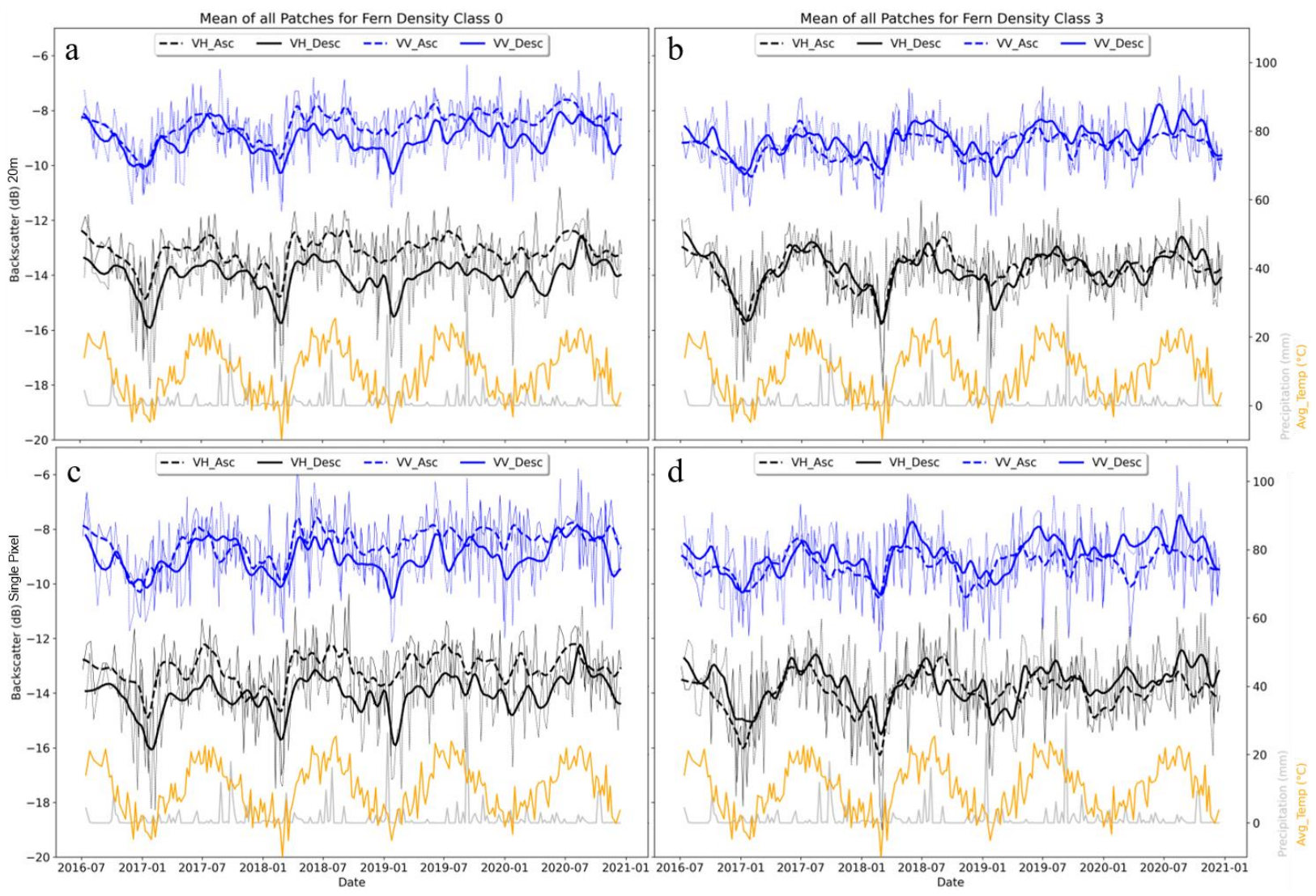

Figure 5: Spatially averaged backscatter time series of the Sentinel-1 C-band signal for the pine forest with no fern present (fern density 0) (a) and pine forest with strong fern undergrowth vegetation (fern density 3) (b) of the $20 \mathrm{~m}$ patches (top). Single pixel equivalent of the same locations below (c, d). Gray and yellow lines represent daily sum of precipitation and daily average of air temperature from a meteo-station nearby.

height in the meteorological summer, the strongest measurable impact is predicted in summer with a smaller impact in autumn as the fern starts to dry out. To validate these hypotheses, we analyzed the difference between the maximally fern-covered (Fig. 3d) sites and areas without undergrowth fern vegetation (Fig. 3a) and compared the difference of backscatter of the four meteorological seasons (Trenberth 1983) for all combinations of acquisition scenarios. To determine statistical significance, ANOVA and Tukey's post-hoc tests were performed.

\section{RESULTS}

This section presents the backscatter analyses for (systematic) influence of fern undergrowth on particular SAR signal configurations. To rule out other external factor as much as possible, the spatial and temporal stability of the data is analyzed as well. The Copernicus Sentinel-1 time series for fern density class 0 and fern density class 3 is shown in Figure 5 in combination with meteorological data. The different acquisition scenarios are highlighted in different colors and line styles.

\subsection{Spatial and temporal stability}

To ensure robust results on the spatial domain, the spatially averaged time series is compared to the analysis of a single pixel (after speckle treatment) time series for each measurement location. The TCD between fern class 0 and fern class 3 is comparable for the northern location with $90 \%$ for fern class 3 and $90.75 \%$ TCD for fern class 0 . Similarly, the first southern location exhibits comparable TCD values between $84.75 \%$ and $85.25 \%$ TCD. The second southern location however shows an increased difference between TCD with $81.5 \%$ tree cover density at fern class 3 and $90 \%$ TCD at fern class 0 .

Figure 5 compares the mean backscatter of locations with no fern present (class 0) (a, c) and areas with dense fern (class 3 ) present (b, d) for the averaged time series of the bounding box (top) as well as for the single pixel analysis (bottom).

The backscatter difference between the spatial average and the single pixel analysis ranges from $-0.02 \mathrm{~dB}$ (VV_Asc.) to $0.02 \mathrm{~dB}$ (VH_Asc) at fern class 0 and from $-0.18 \mathrm{~dB}$ (VH_Asc) to 0.13 dB (VV_Desc) for fern class 3 respectively (Tab. 3, first column). To establish the temporal stability of the data, the time series resolution was reduced two- and fourfold. The results show similar results to the original time series, with backscatter differences between the spatially averaged classes and the single pixels at half temporal resolution of -0.08 (VV_Desc) and $0.04 \mathrm{~dB}$ (VH_Asc) for the fern class 0 and -0.20 (VH_Asc) and $0.15 \mathrm{~dB}$ (VH_Desc) for fern class 3 . At just $25 \%$ of the temporal

Table 3: Comparison of multi-pixel and single-pixel backscatter analysis and simultaneous reduction of temporal resolution to determine spatial and temporal stability, calculated for each single measurement location and then averaged over all sites.

\begin{tabular}{|c|c|c|c|c|c|c|}
\hline & \multicolumn{2}{|c|}{$\begin{array}{c}\text { 20m Patch vs. Single } \\
\text { Pixel Backscatter } \\
\text { Difference (dB) }\end{array}$} & $\begin{array}{c}\text { 20m Patch vs. Single } \\
\text { Pixel Backscatter } \\
\text { Difference (dB) (Half } \\
\text { temporal resolution) }\end{array}$ & $\begin{array}{c}\text { 20m Patch vs. Single } \\
\text { Pixel Backscatter } \\
\text { Difference (dB) (Quarter } \\
\text { temporal resolution) }\end{array}$ \\
\hline $\begin{array}{c}\text { Polarization/ } \\
\text { Orbit }\end{array}$ & $\begin{array}{c}\text { Fern Density } \\
\text { Class 0 }\end{array}$ & $\begin{array}{c}\text { Fern Density } \\
\text { Class 3 }\end{array}$ & $\begin{array}{c}\text { Fern Density } \\
\text { Class 0 }\end{array}$ & $\begin{array}{c}\text { Fern Density } \\
\text { Class 3 }\end{array}$ & $\begin{array}{c}\text { Fern Density } \\
\text { Class 0 }\end{array}$ & $\begin{array}{c}\text { Fern Density } \\
\text { Class 3 }\end{array}$ \\
\hline VH/Ascending & 0.018 & -0.182 & 0.044 & -0.197 & -0.051 & -0.201 \\
\hline VH/Descending & -0.006 & 0.116 & 0.039 & 0.154 & 0.007 & 0.072 \\
\hline VV/Ascending & -0.018 & 0.022 & -0.067 & 0.077 & -0.109 & 0.049 \\
\hline VV/Descending & 0.007 & 0.125 & -0.081 & 0.143 & 0.196 & 0.103 \\
\hline
\end{tabular}



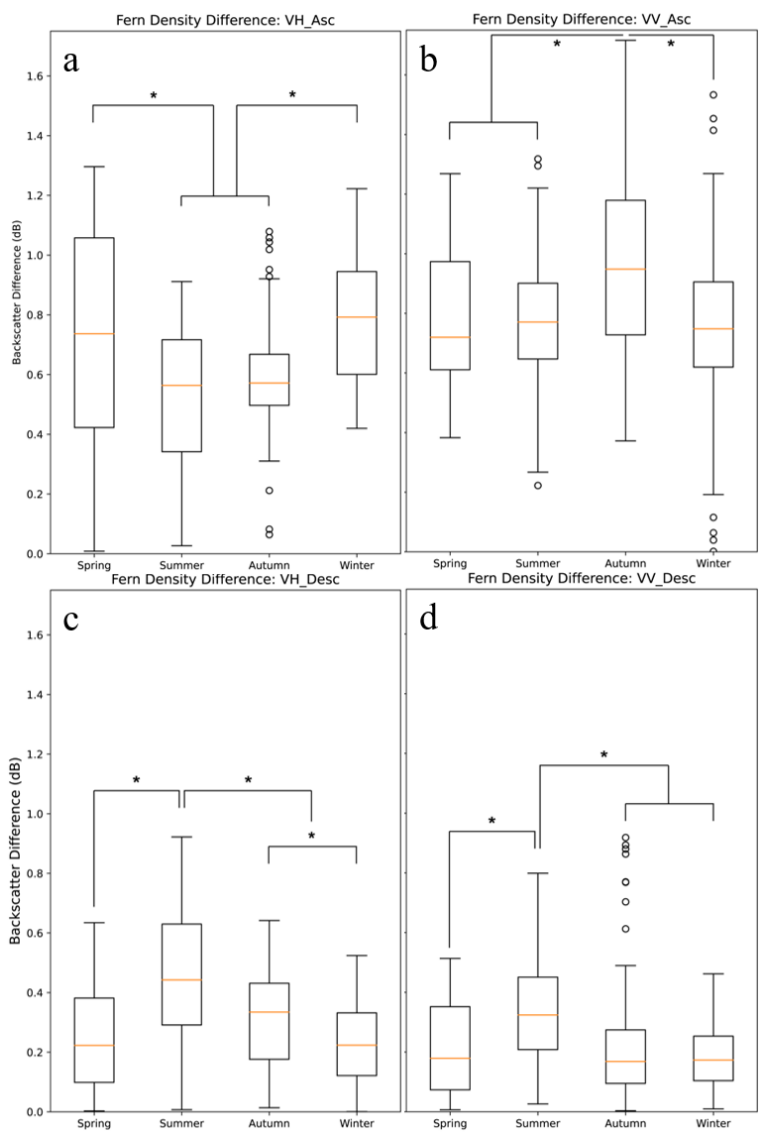

Figure 6: Comparison of absolute backscatter difference between seasons and different acquisition scenarios, asterisk represents statistical significance $(\mathrm{p}<0.05)$.

resolution, a result of -0.11 (VV_Asc) to $0.20 \mathrm{~dB}$ (VV_Desc) for fern class 0 and $-0.2 \mathrm{~dB}$ (VH_Asc) to $0.1 \mathrm{~dB}$ (VV_Desc) difference for fern class 3 was established (Tab. 3).

Compared to Figure 6, the temporal and spatial differences are small enough to only exhibit small influence on the overall analysis. The values in Table 3 could be seen as the spatial and temporal resolution limits of the applied method.

\subsection{Visibility of fern}

A seasonal backscatter signal is observable for all acquisition scenarios and all fern classes (Fig. 5), with a consistently higher backscatter for ascending pass direction compared to descending in fern class 0 . The seasonality in the signal is visually stronger observable in the time series of fern class 3 compared to fern class 0 .

As the growing season of fern starts in April, stronger changes are expected for the meteorological summer and autumn seasons, where the fern undergrowth is present. Seasonal analyses show the strongest backscatter difference between winter-spring (fern off) and summer-autumn (fern on) seasons due to the phenological cycle of fern (Fig. 6).

Overall, there is a bigger backscatter difference apparent between the fern classes in the ascending pass direction compared to descending for all seasons (Fig. 6 and Fig. 7). The mean absolute backscatter difference between fern class 0 and fern class 3 in ascending pass direction ranges from $0.67 \mathrm{~dB}$ (VH_Asc) to 0.79 $\mathrm{dB}$ (VV_Asc), while the backscatter difference in descending pass direction through all seasons ranges from $0.31 \mathrm{~dB}$ (VH_Desc) to $0.21 \mathrm{~dB}$ (VV_Desc). Those values are higher than the detected spatial and temporal variabilities of the signal due to different sampling sizes.

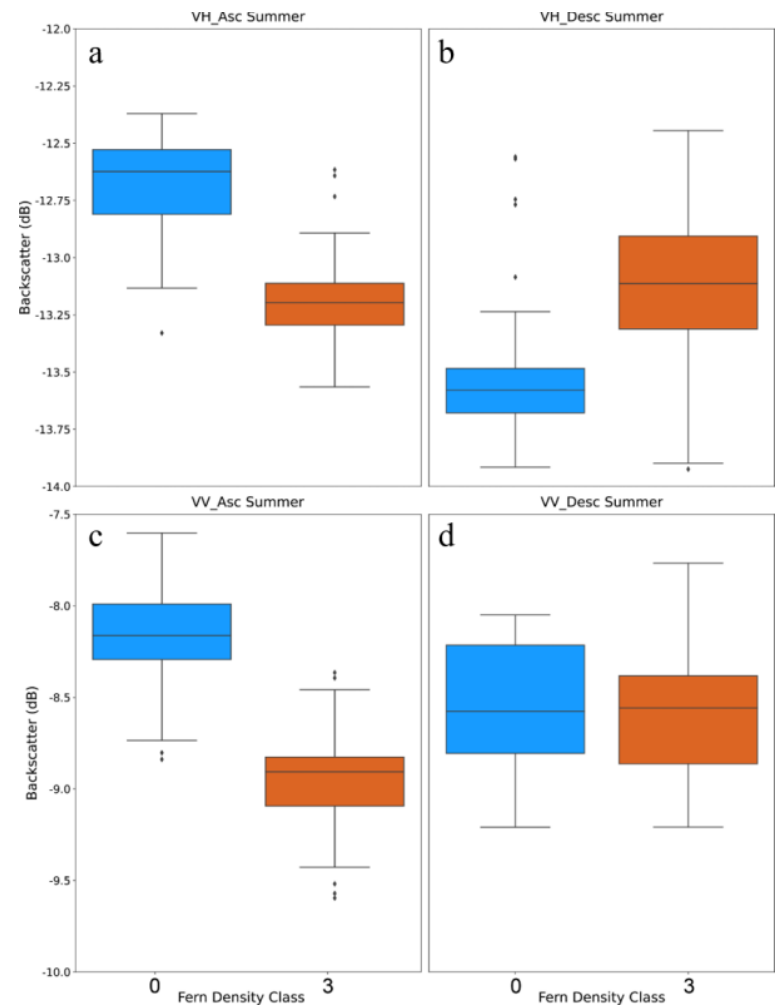

Figure 7: Backscatter difference between Fern class 0 and 3 during summer for all acquisition scenarios.

With that in mind, the relative difference in backscatter between the seasons should provide insight on the actual influence of fern vegetation. As we compare the same datasets at different locations, this difference is not due to the inherent sensor noise level but on physical differences of the observed area.

While the backscatter difference for VH_Asc remains stable in spring and winter, a significant decrease of backscatter difference of $0.20 \mathrm{~dB}$ is observed in summer and autumn (Fig. 6a). With copolarized acquisition and ascending pass direction (VV_Asc) there is a significant difference of median backscatter between autumn and the remaining seasons (increase by $0.20 \mathrm{~dB}$ ), while there is no significant difference between summer and other seasons (Fig. 6b). VH_Desc shows significant backscatter differences between summer and the other three seasons. The increase of backscatter difference in summer amounts to $0.15 \mathrm{~dB}$ compared to the three remaining seasons (Fig. 6d).

As summer is the season with the strongest change as well as biologically the most active, a direct comparison of the backscatter of this season is shown in Figure 7. Whilst the backscatter decreases from no fern (class 0 ) to maximum amount of fern (class 3 ) present for ascending pass directions, it increases slightly for the descending pass direction (Fig. 7). In VH_Asc configuration, there is a significant difference between fern class 0 and 3 with a median backscatter decrease of $0.67 \mathrm{~dB}$ (Fig. 7a). In the descending pass direction and co-polarized time series, the backscatter increases significantly by $0.45 \mathrm{~dB}$ (Fig 7b). For VV_Asc the backscatter in summer decreases significantly from a median of $-8.21 \mathrm{~dB}$ in fern class 0 to a median of $-8.82 \mathrm{~dB}$ in fern class 3, while there is no significant difference observed at VV_Desc (Fig 7c, d). These results indicate that the presence of fern and undergrowth has an influence on the backscatter signal.

\section{DISCUSSION}

In the following, the potential further influences on the backscatter time series, such as moisture content or TCD are 
discussed, as well as their observed seasonal differences. Furthermore, the influence of the acquisition system parameters is discussed, and results are brought into context with related literature.

The results suggest the existence of an influence by fern undergrowth vegetation on the C-band Sentinel-1 SAR signal in our temperate coniferous forest test site. While the absolute difference between forest without fern undergrowth and forest with strong fern vegetation only ranges from 0.4 to $0.8 \mathrm{~dB}$ in summer, the relative difference between seasons allows the detection of systematic seasonal changes indicating the influence of fern vegetation. Dense time series can be used to identify small changes in backscatter over time to establish a stable pattern of difference between areas with no fern and areas with strong fern presence in the undergrowth vegetation. As an evergreen forest, the influence of seasonally-induced structural changes in the tree canopy should be minimal with predictable temporal radar signatures (Dostálová et al. 2021). This also allows the extraction of inter-seasonal differences for further analysis using phenological information. The spatial and temporal analyses also show a stable signal over long time periods of multiple years, with maximum variations $0.2 \mathrm{~dB}$ between the different spatial and temporal samples.

It is important to consider the relative radiometric accuracy of Sentinel-1 when analyzing small backscatter changes between areas (Schmidt et al. 2018). The temporal and spatial accuracy analysis was performed to estimate the general accuracy limits of this approach. Since we use temporally averaged data over long time series, resulting in backscatter differences above the stated accuracy limits ( 0.1 dB) (Schmidt et al., 2018; El Hajj et al., 2019), we assumed, that the resulting backscatter difference can be traced back to a natural cause and not to a system effect.

One key finding of this study is the difference in backscatter change depending on the acquisition scenarios of the SAR data for this kind of analysis, with the ascending pass exhibiting considerably higher backscatter change than the descending pass direction. As the acquisition times for the ascending pass direction are late afternoon (after $5 \mathrm{pm}$ ) and the descending scenes are acquired in early morning (around 5:30 am), external factors such as evapotranspiration could play a role in the different behaviors (Mahdavi et al. 2019). To enable a detailed analysis, a more in-depth investigation of the soil and vegetation parameters, such as soil moisture and temperature or VWC and plant structure would be necessary. For the ascending pass direction and summer season, the backscatter is significantly lower for fern class 3 compared to fern class 0 , while the opposite effect can be observed for VH_Desc. The authors still investigate these contradicting results because attenuation in VV polarization or incidence angle influences can be ruled out. Interestingly, the backscatter change between fern classes did not follow a fixed pattern when compared by polarization. The pass direction seems to dominate the change of backscatter difference between classes.

The backscatter difference for VV_Desc stays under $0.4 \mathrm{~dB}$ for each season. This constellation also shows the least change between fern classes in summer with no significant difference between fern class 0 and fern class 3 in summer (Fig. 7d). For the remaining acquisition scenarios, the change in backscatter difference is sufficiently high to warrant an analysis and are thus likely a result of fern influence.

With only three measurement sites for fern class 3 , the significance and transferability of the results is limited. Furthermore, the field campaign was only carried out in 2020, so there is only one year of phenological fern data compared to 4.5 years of SAR data.

The heterogenous undergrowth vegetation occurring at areas with no fern present (see Fig. 2a) could also influence the backscatter signal, but they do not grow to equivalent heights as the eagle fern. Additionally, the areas of dense fern growth are limited to small patches of a few hundred square meters, making analysis with more than six to nine Sentinel-1 pixels per location impossible. As the spatial accuracy analysis has shown, the overall signal is stable over a wider area allowing for such analyses. Especially, the spatial analysis showed that the spatial signal is slightly more stable for fern class 0 than for fern class 3 , suggesting that the areas considered covered with fern could contain mixed pixels. Garestier et al. (2008) shows that an open canopy is necessary for detailed undergrowth analyses using shorter wavelengths, like C- or X-band. The TCD dataset was used to compare the tree cover density for each measurement location. Vastly differing values could indicate lower comparability of canopy cover cases. Two of the three used in situ sites reveal TCD-values with a difference of one percent between fern class 0 and 3, while one location shows a difference of $8.5 \%$ between the fern classes. This could lead to additional signal variations that needs to be considered.

Other external factors such as terrain should not influence the results, as the whole study site shows gentle terrain with no large local incidence angle changes for the different orbits (acquisition scenarios).

\section{CONCLUSION AND OUTLOOK}

In this study, we analyzed dense Sentinel-1 backscatter time series to characterize influences of fern undergrowth vegetation in a coniferous forest on the C-band signal. A comprehensive investigation of seasonal effects and influences of different acquisition scenarios was performed. As the strongest signal was expected during the active growing season, the meteorological summer was investigated in detail and revealed a significant backscatter difference between areas without fern presence and areas with strong fern presence. An additional analysis of different spatial and temporal samplings showed that these finding holds true for different spatio-temporal inputs.

We understood that the strength of this effect mainly depends on the acquisition scenarios of the SAR signal. These results suggest further influences by height, structure and density of the forest, through which the signal passes to the undergrowth medium.

For a more in-depth analysis of these further signal influences, a follow-on study will isolate potentially influencing factors such as TCD, soil and vegetation moisture. Furthermore, the expansion of the number of measurement sites should strengthen the statistical significance of the presented findings.

\section{ACKNOWLEDGEMENTS}

The authors would like to thank the DLR Institute of Data Science for the app development for the fern measurements, which was tested and used during field campaigns. Special thanks to Mona Reichel for supporting the statistical analysis of the data.

\section{REFERENCES}

Bauer, L. (2013): Vergleichende Hydrogeographie von Thüringen - ein wasserhistorischer Rückblick. Jena, Suhl: Arbeitsgruppe Artenschutz Thüringen e. V.

Copernicus Land Monitoring Service (2020): Tree Cover Density 2018. Available online at https://land.copernicus.eu/paneuropean/high-resolution-layers/forests/tree-coverdensity/status-maps/tree-cover-density-2018, updated on 4/16/2021, checked on 4/16/2021. 
Cremer, F.; Urbazaev, M.; Cortes, J.; Truckenbrodt, J.; Schmullius, C.; Thiel, C. (2020): Potential of Recurrence Metrics from Sentinel-1 Time Series for Deforestation Mapping. In IEEE J. Sel. Top. Appl. Earth Observations Remote Sensing 13, pp. 5233-5240. DOI: 10.1109/JSTARS.2020.3019333.

Dostálová, A.; Lang, M.; Ivanovs, J.; Waser, L. T.; Wagner, W. (2021): European Wide Forest Classification Based on Sentinel1 Data. In Remote Sensing 13 (3), p. 337. DOI: $10.3390 /$ rs 13030337 .

Dostálová, A.; Wagner, W.; Milenković, M.; Hollaus, M. (2018): Annual seasonality in Sentinel-1 signal for forest mapping and forest type classification. In International Journal of Remote $\begin{array}{llll}\text { Sensing } & 39 & (21), & \text { pp. 7738-7760. }\end{array}$ 10.1080/01431161.2018.1479788.

Dubois, C.; Mueller, M. M.; Pathe, C.; Jagdhuber, T.; Cremer, F.; Thiel, C.; Schmullius, C. (2020): CHARACTERIZATION OF LAND COVER SEASONALITY IN SENTINEL-1 TIME SERIES DATA. In ISPRS Ann. Photogramm. Remote Sens. Spatial Inf. Sci. V-3-2020, pp. 97-104. DOI: 10.5194/isprsannals-V-3-2020-97-2020.

El Hajj, M.; Baghdadi, N.; Bazzi, H.; Zribi, M. (2019): Penetration Analysis of SAR Signals in the C and L Bands for Wheat, Maize, and Grasslands. In Remote Sensing 11 (1), p. 31. DOI: $10.3390 /$ rs 11010031.

Frison, P.-L.; Fruneau, B.; Kmiha, S.; Soudani, K.; Dufrêne, E.; Le Toan, T. et al. (2018): Potential of Sentinel-1 Data for Monitoring Temperate Mixed Forest Phenology. In Remote Sensing 10 (12), p. 2049. DOI: 10.3390/rs10122049.

Garestier, F.; Dubois-Fernandez, P. C.; Papathanassiou, K. P. (2008): Pine Forest Height Inversion Using Single-Pass X-Band PolInSAR Data. In IEEE Trans. Geosci. Remote Sensing 46 (1), pp. 59-68. DOI: 10.1109/TGRS.2007.907602.

Holmgren, P.; Thuresson, T. (1998): Satellite remote sensing for forestry planning - A review. In Scandinavian Journal of Forest Research $13 \quad$ (1-4), pp. 90-110. DOI: $10.1080 / 02827589809382966$.

Joshi, N.; Mitchard, E. T. A.; Brolly, M.; Schumacher, J.; Fernández-Landa, A.; Johannsen, V. K. et al. (2017): Understanding 'saturation' of radar signals over forests. In Scientific reports 7 (1), p. 3505. DOI: 10.1038/s41598-01703469-3.

Mahdavi, S.; Amani, M.; Maghsoudi, Y. (2019): The effects of orbit type on synthetic aperture RADAR (SAR) backscatter. In Remote Sensing Letters 10 (2), pp. 120-128. DOI: 10.1080/2150704X.2018.1530481.

Monteith, A. R.; Ulander, L. M. H. (2018): Temporal Survey of P- and L-Band Polarimetric Backscatter in Boreal Forests. In IEEE J. Sel. Top. Appl. Earth Observations Remote Sensing 11 (10), pp. 3564-3577. DOI: 10.1109/JSTARS.2018.2814825.

Quegan, S.; Le Toan, T.; Yu, J. J.; Ribbes, F.; Floury, N. (2000): Multitemporal ERS SAR analysis applied to forest mapping. In IEEE Trans. Geosci. Remote Sensing 38 (2), pp. 741-753. DOI: $10.1109 / 36.842003$.

Rütschi, M.; Schaepman, M. E.; Small, D. (2018): Using Multitemporal Sentinel-1 C-band Backscatter to Monitor Phenology and Classify Deciduous and Coniferous Forests in Northern Switzerland. In Remote Sensing 10 (2), p. 55. DOI: $10.3390 / \mathrm{rs} 10010055$.
Schmidt, K.; Tous Ramon, N.; Schwerdt, M. (2018): Radiometric accuracy and stability of sentinel-1A determined using point targets. In Int. J. Microw. Wireless Technol. 10 (5-6), pp. 538 546. DOI: $10.1017 / \mathrm{S} 1759078718000016$.

Shimada, M.; Isoguchi, O.; Motooka, T.; Shiraishi, T.; Mukaida, A.; Okumura, H. et al. (2011): Generation of $10 \mathrm{~m}$ resolution PALSAR and JERS-SAR mosaic and forest/non-forest maps for forest carbon tracking. In : 2011 IEEE International Geoscience 07/2011, pp. 3510-3513.

Stendardi, L.; Karlsen, S.; Niedrist, G.; Gerdol, R.; Zebisch, M.; Rossi, M.; Notarnicola, C. (2019): Exploiting Time Series of Sentinel-1 and Sentinel-2 Imagery to Detect Meadow Phenology in Mountain Regions. In Remote Sensing 11 (5), p. 542. DOI: 10.3390/rs11050542.

Thiel, C.; Müller, M. M.; Berger, C.; Cremer, F.; Dubois, C.; Hese, S. et al. (2020): Monitoring Selective Logging in a PineDominated Forest in Central Germany with Repeated Drone Flights Utilizing A Low Cost RTK Quadcopter. In Drones 4 (2), p. 11. DOI: $10.3390 /$ drones4020011.

Townsend, P. A. (2002): Relationships between forest structure and the detection of flood inundation in forested wetlands using C-band SAR. In International Journal of Remote Sensing 23 (3), pp. 443-460. DOI: 10.1080/01431160010014738.

Trenberth, K. E. (1983): What are the Seasons? In Bull. Amer. Meteor. Soc. 64 (11), pp. 1276-1282. DOI: 10.1175/15200477(1983)064<1276:WATS >2.0.CO;2.

Truckenbrodt, J.; Cremer, F.; Baris, I.; Eberle, J. (2019): Pyrosar: a framework for large-scale sar satellite data processing. Munich, 19-21 Feb, 2019. Big Data from Space. Luxembourg: Publications Office of the European Union.

Vreugdenhil, M.; Wagner, W.; Bauer-Marschallinger, B.; Pfeil, I.; Teubner, I.; Rüdiger, C.; Strauss, P. (2018): Sensitivity of Sentinel-1 Backscatter to Vegetation Dynamics: An Austrian Case Study. In Remote Sensing 10 (9), p. 1396. DOI: $10.3390 /$ rs 10091396

White, J. C.; Coops, N. C.; Wulder, M. A.; Vastaranta, M.; Hilker, T.; Tompalski, P. (2016): Remote Sensing Technologies for Enhancing Forest Inventories: A Review. In Canadian Journal of Remote Sensing 42 (5), pp.619-641. DOI: 10.1080/07038992.2016.1207484. 